\title{
Properties of alumina films prepared by atmospheric pressure metal-organic chemical vapour deposition
}

\author{
V. A. C. Haanappel, H. D. van Corbach, T. Fransen* and P. J. Gellings \\ Unitersity of Twente, Department of Chemical Technology, P.O. Box 217, 7500 AE Enschede (Netherlands)
}

(Received June 21, 1993; accepted in final form July 12, 1993)

\begin{abstract}
Thin alumina films were deposited at low temperatures $\left(290-420^{\circ} \mathrm{C}\right)$ on stainless steel, type AISI 304 . The deposition process was carried out in nitrogen by metal-organic chemical vapour deposition using aluminium tri-sec-butoxide. The film properties including the protection of the underlying substrate against high temperature corrosion, the chemical composition of the film, the microstructure, and the refractive index were investigated. The activation energy for the heterogeneous reaction was $83 \pm 5 \mathrm{~kJ} \mathrm{~mol}^{-1}$. Corrosion experiments, performed at $450^{\circ} \mathrm{C}$ in a hydrogen sulphide containing gas, showed that the amount of corrosion products of an alumina film $\left(0.20 \pm 0.05 \mathrm{mg} \mathrm{cm}^{-2}\right)$-AISI 304 combination decreased with increasing deposition temperature. The alumina films, even those deposited at $420^{\circ} \mathrm{C}$, exhibited an amorphous structure, in agreement with the index of refraction. Transmission electron microscopy analysis revealed that extremely fine $\gamma$-alumina was formed. Only $\mathrm{OH}$ groups were found as an impurity in the oxide film. No carbon was detected.
\end{abstract}

\section{Introduction}

Recently, much research has been performed on the deposition from the gas phase of several metal oxides, such as $\mathrm{SiO}_{2}, \mathrm{Cr}_{2} \mathrm{O}_{3}, \mathrm{TiO}_{2}$, and $\mathrm{Al}_{2} \mathrm{O}_{3}$ by means of metal alkoxides. The synthesis of metal alkoxides was extensively investigated by Bradley et al. [1, 2]. The metal alkoxides, which can be considered to be derivatives of an alcohol in which the hydrogen atom of the alcohol group is replaced by the metal $\mathbf{M}$, have excellent properties regarding the formation of several metal oxides. The stabilities of these various oxides as a function of the temperature are given in EllinghamRichardson diagrams [3].

For the deposition of alumina films several metalorganic compounds were investigated [4-15], for example trimethylaluminium, tripropylaluminium, aluminium tri-sec-butoxide (ATSB), aluminium triisopropoxide, aluminium triethoxide and aluminium tri-tert-butoxide. The trivalent metal alkoxides are the most stable metal organic compounds and can be heated without decomposition. Another advantage is the satisfactory stoichiometric requirement for the formation of oxide. In general, these metal-organic compounds contain sufficient oxygen for the formation of the desired oxide. Also, the physical properties of the metal alkoxides such as vapour pressure, melting point and boiling point, and liquid or solid state at room temperature have to be considered

\footnotetext{
*Author to whom correspondence should be addressed.
}

before a choice will be made regarding the most promising precursor.

The use of the metal alkoxide ATSB was reported only by Okuyama et al. [16] and Kodas et al. [17] for the production of ultrafine alumina aerosol particles by thermal decomposition of ATSB. Physical properties of ATSB and some other aluminium alkoxides were reported by Sladek and Gibert [18] and Wilhoit [19] regarding the equilibrium vapour pressure.

Alumina films have been employed in semiconductor device applications as intermetal dielectrics for silicon integrated circuits and passivation dielectrics for GaAs [20]. They may be useful in semiconductor device applications as a passivating layer because of their impermeability to the diffusion of alkaline ions and other impurities [21], in contrast with silicon oxide which has a high permeability to alkali ions such as sodium [22]. Alumina films can also be used as coatings in the field of high temperature corrosion, as reported by Morssinkhof [9].

Several deposition techniques are today available to deposit thin oxide films, such as laser-enhanced or assisted, plasma-enhanced, low pressure, metal-organic, and magnetron plasma chemical vapour deposition. The metal-organic chemical vapour deposition (MOCVD) technique for alumina films consists of the decomposition of the metal-organic precursor in the vapour phase. This process can be carried out with or without oxygen at relatively low temperatures. 
The aim of the present investigation was to study the development, analysis and characterization of thin alumina films, applied on AISI 304. The alumina films have been deposited by the thermal decomposition of ATSB in a nitrogen atmosphere under atmospheric pressure. Material properties, such as protectiveness against high temperature corrosion, index of refraction, structure and chemical composition, were investigated as function of the deposition temperature.

\section{Experimental details}

Alumina films were deposited by means of atmospheric pressure MOCVD using ATSB (Janssen Chimica) and dried nitrogen gas. The substrate used in the experiments was a stainless steel, type AISI 304, which was cut from an electropolished metal sheet and ultrasonically cleaned in, consecutively, hexane and ethanol.

A schematic diagram of the experimental set-up was shown in a previous paper [23]. The ATSB is introduced in the furnace by passing nitrogen gas through the ATSB bubbler with an equilibrium vapour pressure of ATSB at $138^{\circ} \mathrm{C}$ of $0.13 \mathrm{kPa}(1.0 \mathrm{mmHg})$. The ATSB flow rate is adjusted by controlling the flux of nitrogen gas through the ATSB bubbler at atmospheric pressure. This gas mixture was added to the main nitrogen flow which enters the reaction chamber. The flow rates were controlled by using mass flow controllers (Brooks 5850TR). The deposition reaction was carried out in a quartz tube with a diameter of $45 \mathrm{~mm}$. The uniform temperature zone in the reactor is $120 \mathrm{~mm}$. The specimens were attached to a ceramic tube with a thermocouple inside, parallel to the gas flow, in order to measure the substrate temperature and to control the furnace temperature. (Standard conditions were as follows: substrate temperature $330^{\circ} \mathrm{C}$; ATSB temperature, $138^{\circ} \mathrm{C}$; flow rate, 6.51 $\min ^{-1}$ (standard temperature and pressure.) The deposition rate of the films on the metallic substrate was determined by weighing the samples before and after the deposition. In the experiments specimens were used with alumina films of $0.20 \pm 0.05 \mathrm{mg} \mathrm{cm}^{-2}$.

Corrosion experiments were performed in order to investigate the protective capacity, i.e. the porosity, of the films against aggressive gas components such as oxygen and sulphur at high temperatures and were carried out in a closed system for $24 \mathrm{~h}$. The system was first flushed with argon for $20 \mathrm{~h}$ with a flow rate of 161 $\mathrm{h}^{-1}$. The argon was saturated with water at $15^{\circ} \mathrm{C}$. After this, a mixture of $5 \% \mathrm{H}_{2} \mathrm{~S}$ in $\mathrm{H}_{2}$ with a flow rate of 41 $\mathrm{h}^{-1}$ was introduced in the argon flow. After $2 \mathrm{~h}$, in order to stabilize the flow, the furnace was heated to the test temperature $\left(450^{\circ} \mathrm{C}\right)$. The whole system was flushed for another $2 \mathrm{~h}$ and then closed. It was found previously that no relevant difference in corrosion rate and corrosion products was obtained between a closed system and a system with a continuous flow, if the reactive gas consumption did not exceed $20 \%$.

The morphology and the composition of the corroded specimens were investigated by means of optical and scanning electron microscopy (JEOL M 35 CF), the latter equipped with an energy-dispersive X-ray (EDX) analysis system (Kevex Delta, class III).

To characterize the chemical composition and the depth profile, the alumina films were analysed using a Perkin-Elmer PHI 600 scanning Auger multiprobe. Alternate sputtering and Auger analysis were used during in-depth analysis. The functional groups including hydrogen-containing bonds within the films were measured by Fourier transform IR (FTIR) spectroscopy, using a Nicolet 20 SX FTIR apparatus. Because of the non-transparency of the specimens, the spectrometer was equipped with a diffuse reflection cell [9]. The microstructure of the films was investigated by X-ray diffraction (XRD), using a Philips PW 1710 X-ray diffractometer with monochromatic $\mathrm{Cu} \mathrm{K} \alpha$ radiation and a high resolution transmission electron microscope, model JEOL $200 \mathrm{CX}$. The refractive index of the deposited films was measured with a Plasmos ellipsometer (SD 2002) at a wavelength of $6328 \AA$ using an $\mathrm{He}-\mathrm{Ne}$ laser source. The angle of incidence was $70^{\circ}$.

\section{Results}

The Arrhenius plot giving the effect of the deposition temperature $\left(290-420^{\circ} \mathrm{C}\right)$ on the deposition rate (milligrams per square centimetre per hour) is shown in Fig. 1. The experimental activation energy for the heterogeneous reaction, calculated from the region representing rate control by reaction, is $83 \pm 5 \mathrm{~kJ} \mathrm{~mol}^{-1}$. This figure shows that a further increase in temperature results in a deposition rate less dependent on the temperature. In

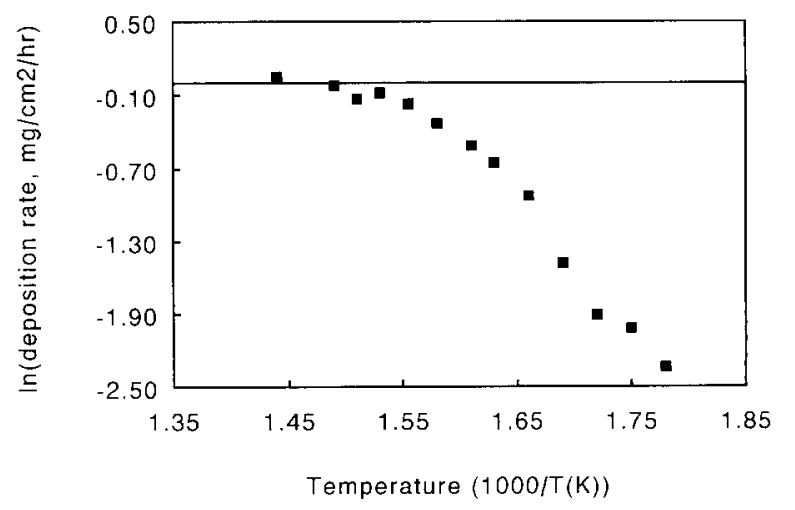

Fig. 1. Deposition rate of alumina as a function of the deposition temperature (Arrhenius curve). 
addition, it was found that the growth rate decreases at even higher deposition temperatures and becomes irreproducible. These data are not presented in the figure.

Corrosion studies were performed in hydrogen sulphide containing gas atmospheres. The effect of the deposition temperature on the relative weight gain (ratio between the weight gains of a coated and an uncoated sample after the corrosion experiments) is shown in Fig. 2. From this figure it is clear that the amount of corrosion products, formed by the presence of pinholes and cracks, tends to decrease with increasing deposition temperature. In Fig. 3 scanning electron microscopy (SEM) pictures of the surface of sulphidized samples are shown. These figures represent the surface of a sample coated under standard conditions (see experimental details) and at deposition temperatures ranging from

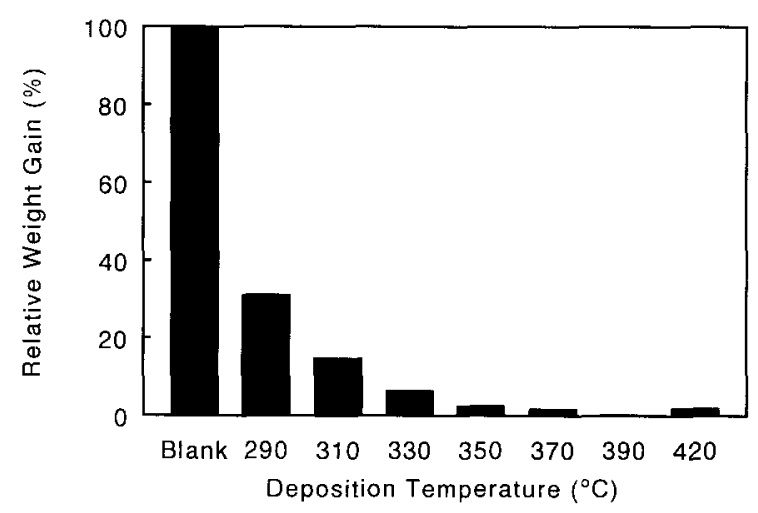

Fig. 2. Histogram of the relative weight gain (per cent) of the specimens (after $24 \mathrm{~h}$ sulphidation at $450^{\circ} \mathrm{C}$ ) as a function of the deposition temperature $\left(\mathrm{Al}_{2} \mathrm{O}_{3}\right.$ on AISI 304).
330 to $420^{\circ} \mathrm{C}$. At higher deposition temperatures the corrosion attack decreases, especially as a result of reduced porosity. Cracks in the alumina films are still present, even at high deposition temperatures, and are responsible for the chain-like corrosion products, which are more pronounced near the edges.

To analyse the composition and the depth profile of the deposited alumina layers Auger electron spectroscopy (AES) in conjunction with ion sputtering was used. In Fig. 4(a) the steady state Auger spectrum (survey scan) is shown of the alumina film deposited at $400{ }^{\circ} \mathrm{C}$. After one or more sputtering cycles (one cycle corresponds to 1 min of sputtering at a rate of $44 \mathrm{~nm} \mathrm{~min}{ }^{-1}$ ) no carbon was detected above the background level of the equipment. Figure 4(b) shows the AES depth profile of the same sample with a thickness of about $0.5 \mu \mathrm{m}$. In this figure the Auger peak-to-peak height ratio is given as function of the sputtering depth. Also, at lower deposition temperatures, even at $300^{\circ} \mathrm{C}$, no carbon was found in the alumina film. Figure 5(a) shows a steady state Auger spectrum (survey scan) without sputtering of the alumina-deposited specimens at $330^{\circ} \mathrm{C}$. In this figure the carbon peak was detected just above the background level but disappeared after one sputtering cycle. Figure $5(\mathrm{~b})$ shows a survey scan after $0.3 \mu \mathrm{m}$ of sputtering and Fig. 5(c) gives the depth profile of the alumina-deposited specimen.

FTIR spectroscopy was used to identify the functional groups in the alumina film, including hydrogen atoms, which are not detectable by SEM, EDX or AES. Figure 6 shows the FTIR absorbance spectra of the alumina films on AISI 304 as a function of the deposition temperature.

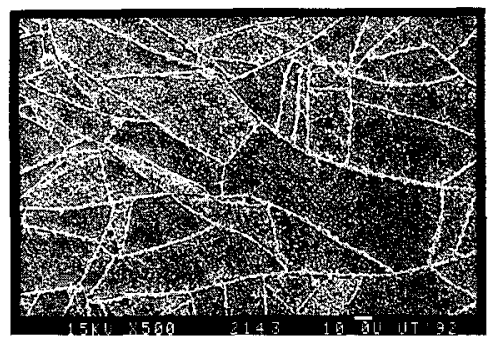

(a)

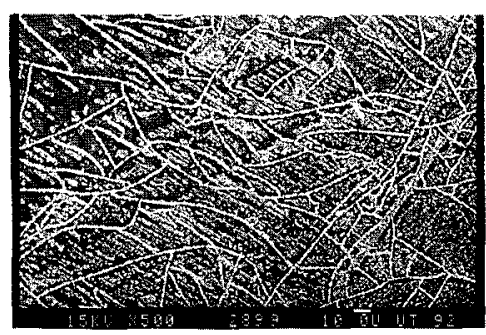

(c).

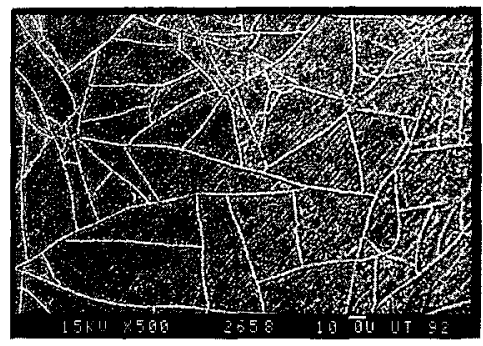

(b)

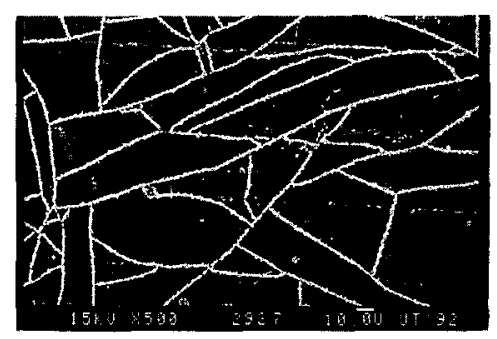

(d)

Fig. 3. SEM images of the surface morphology of coated samples after $24 \mathrm{~h}$ of sulphidation at $450^{\circ} \mathrm{C}$ for deposition temperatures of (a) $330^{\circ} \mathrm{C}$, (b) $370^{\circ} \mathrm{C}$, (c) $400^{\circ} \mathrm{C}$ and (d) $420^{\circ} \mathrm{C}$. 

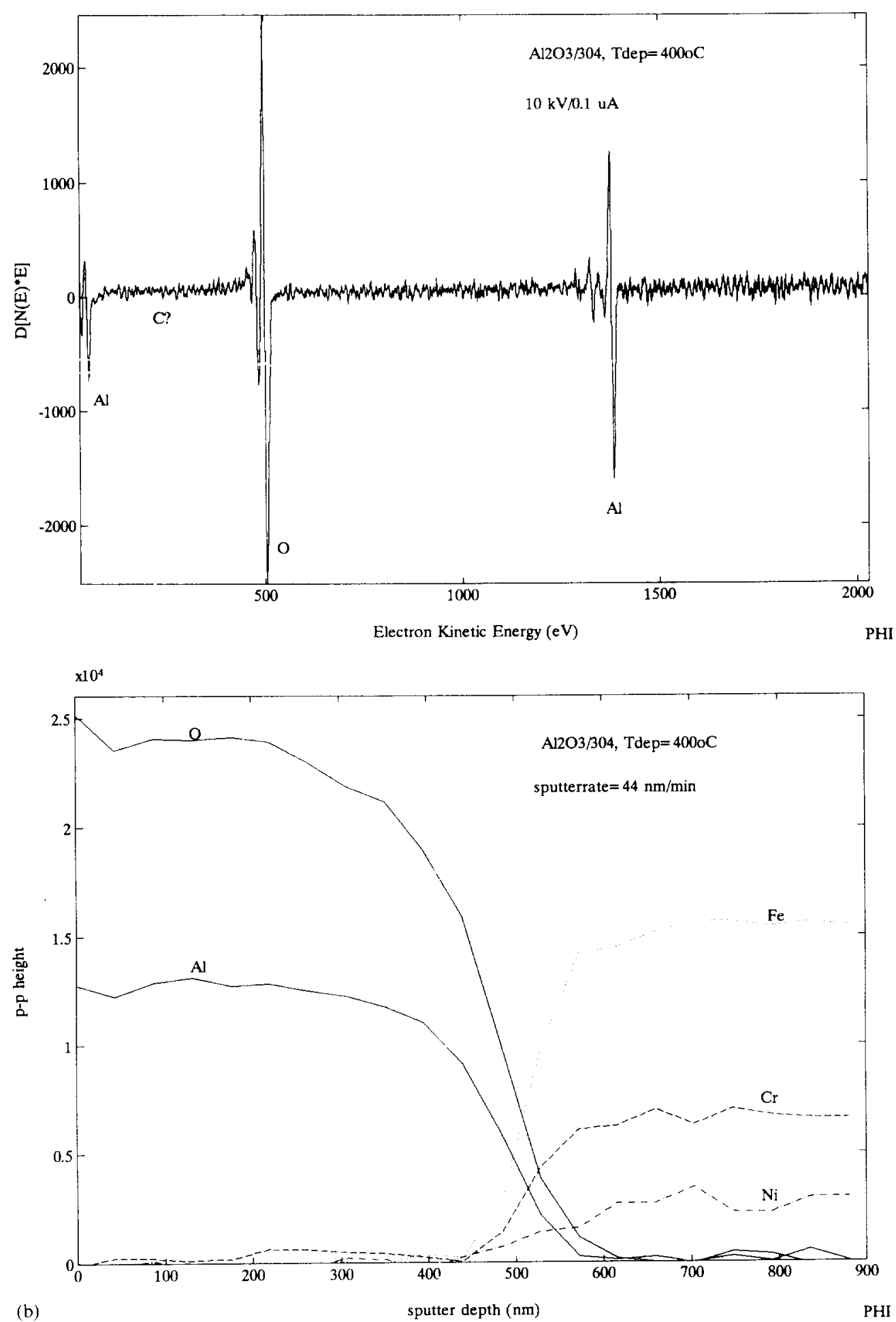

Fig. 4. AES analysis of the alumina film on AISI 304, deposited at $400^{\circ} \mathrm{C}$ : (a) AES survey scan; (b) AES depth profile of the alumina film.

Two specific absorbance bands with wavenumbers of approximately $900-950 \mathrm{~cm}^{-1}$ and $3000-3700 \mathrm{~cm}^{-1}$ were found, indicative of the $\mathrm{Al}-\mathrm{O}$ and $\mathrm{H}-\mathrm{O}$ bonds respectively. The peak around $900-950 \mathrm{~cm}^{-1}$ is not found in the literature as one characteristic band for the $\mathrm{Al}-\mathrm{O}$ bond. Nevertheless, this peak is considered as a characteristic peak for the alumina film [9]. The $\mathrm{H}-\mathrm{O}$ IR absorbance band decreases in intensity with increasing deposition temperature. Furthermore, it is observed that the absorbance bands around $900-950 \mathrm{~cm}^{-1}$ increase in 


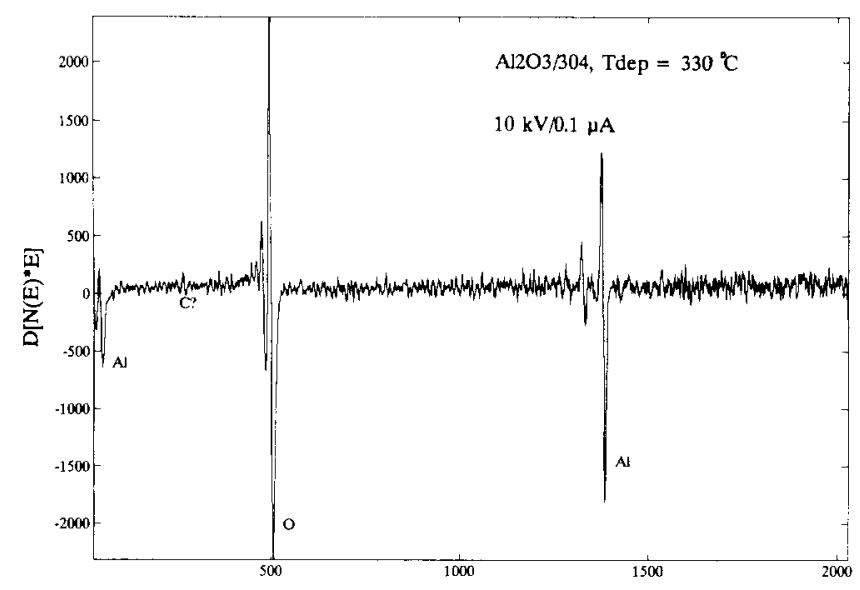

(a)

Electron Kinetic Energy (eV)
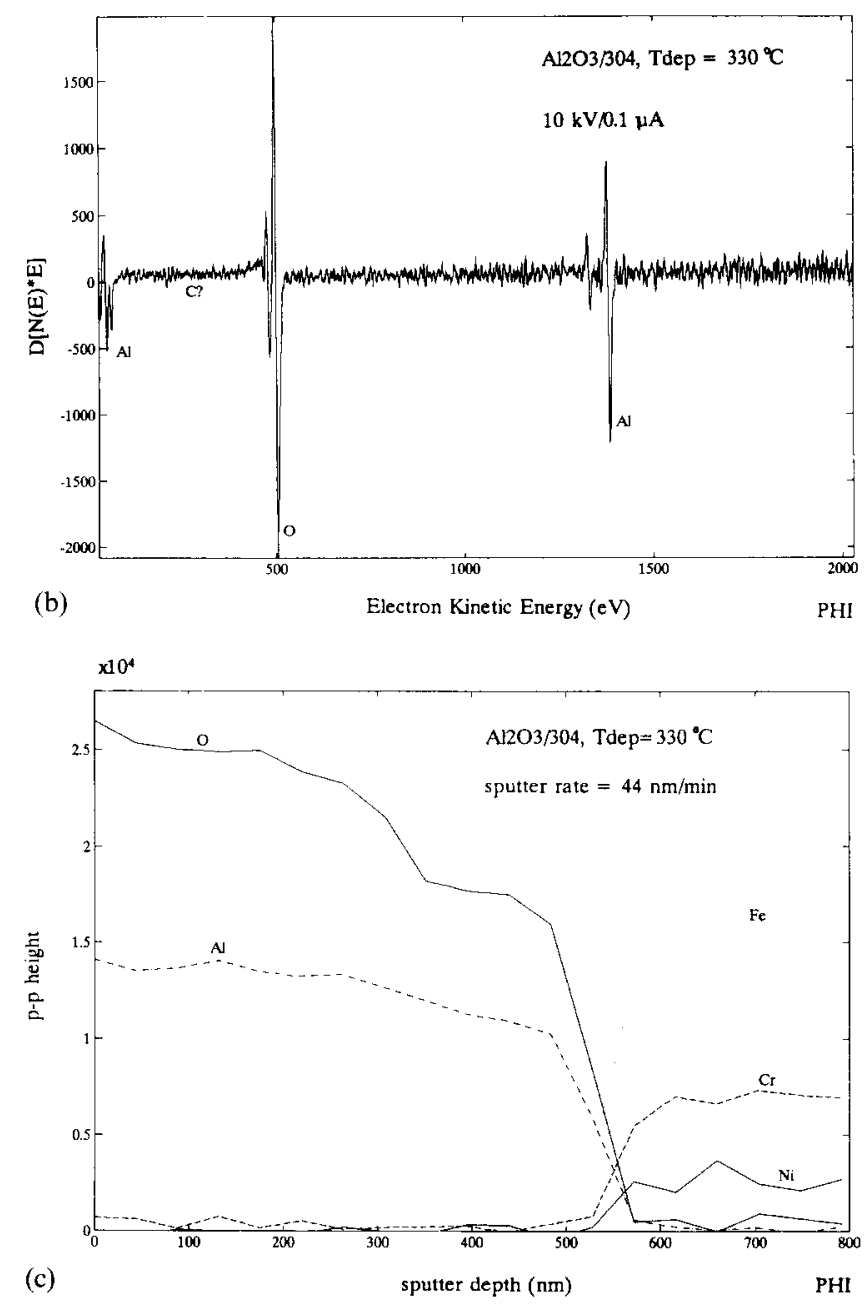

Fig. 5. AES analysis of the alumina film on AISI 304, deposited at $330^{\circ} \mathrm{C}$ : (a) AES survey scan; (b) AES survey scan after $0.3 \mu \mathrm{m}$ of sputtering; (c) AES depth profile of the alumina film.

intensity and shift towards higher wavenumbers with higher deposition temperatures. Figure 7 shows the wavenumber of the $\mathrm{Al}-\mathrm{O}$ bond as function of the deposition temperature.

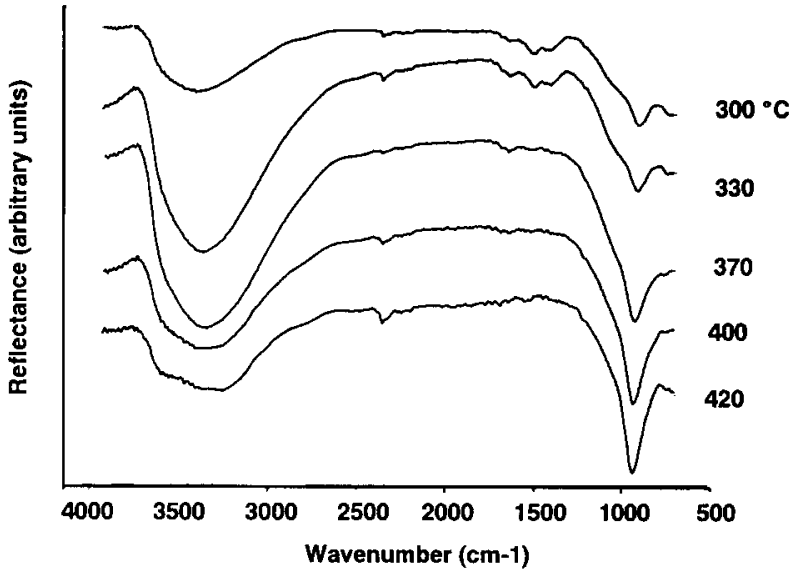

Fig. 6. FTIR absorbance spectra of alumina films deposited at different deposition temperatures.

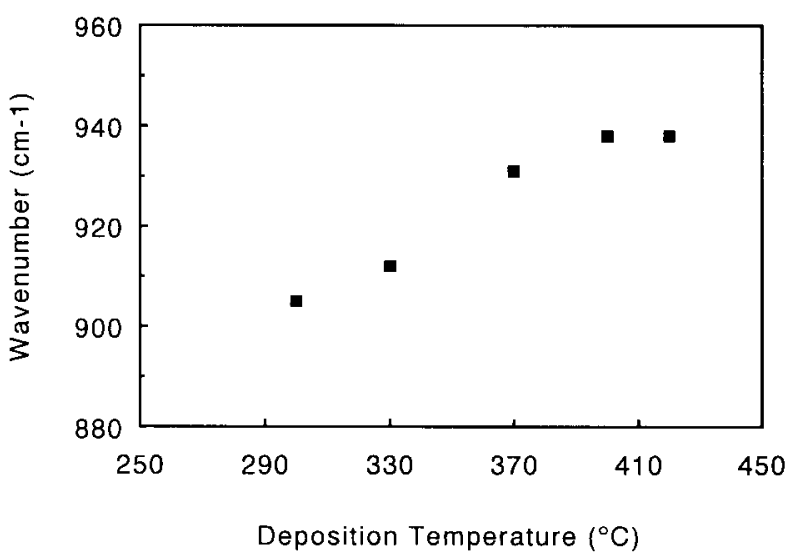

Fig. 7. Peak position of the $\mathrm{Al}-\mathrm{O}$ bond, obtained from the FTIR absorbance spectra of alumina films, deposited at different deposition temperatures.

The microstructure of the alumina films was investigated by XRD. From the XRD patterns of the alumina films deposited at various temperatures $\left(290-420^{\circ} \mathrm{C}\right)$ no crystalline phase could be determined. This indicates that the film has an amorphous structure. Figure 8 shows transmission electron micrographs of the alumina oxide deposited at $330^{\circ} \mathrm{C}$. From this figure it is seen that at a deposition temperature of $330^{\circ} \mathrm{C}$ TEM observations provide electron diffraction ring patterns revealing an extremely fine grain size of the alumina; between 8 and $20 \mathrm{~nm}$.

The refractive indices were measured with the Plasmos ellipsometer and are shown in Fig. 9. In this figure the variation in the refractive index of the alumina films is given as a function of the deposition temperature. The apparent index of refraction was found to vary in the range $1.53-1.60$, increasing with the deposition temperature of the alumina film in nitrogen. It was also found that the refractive index did not change, within the accuracy of the measurements, with coating thickness. 


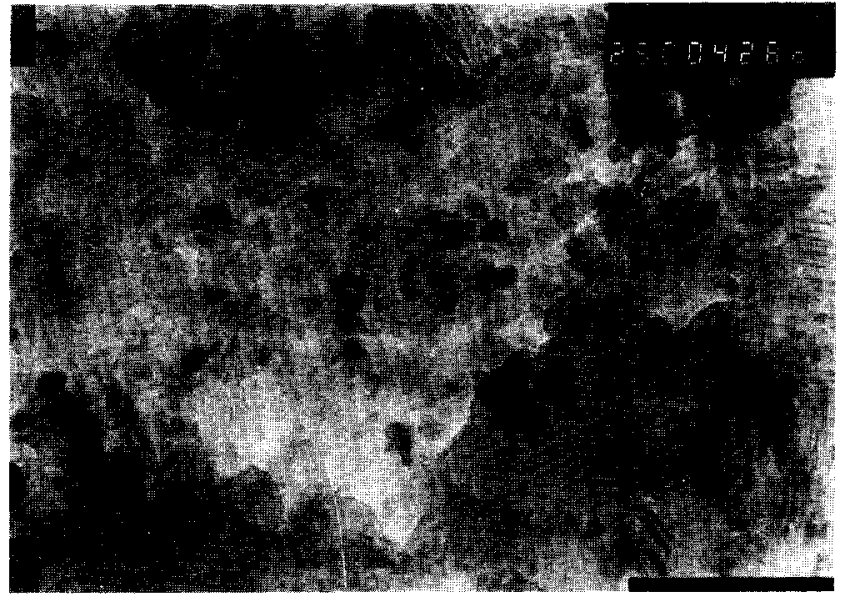

(a)

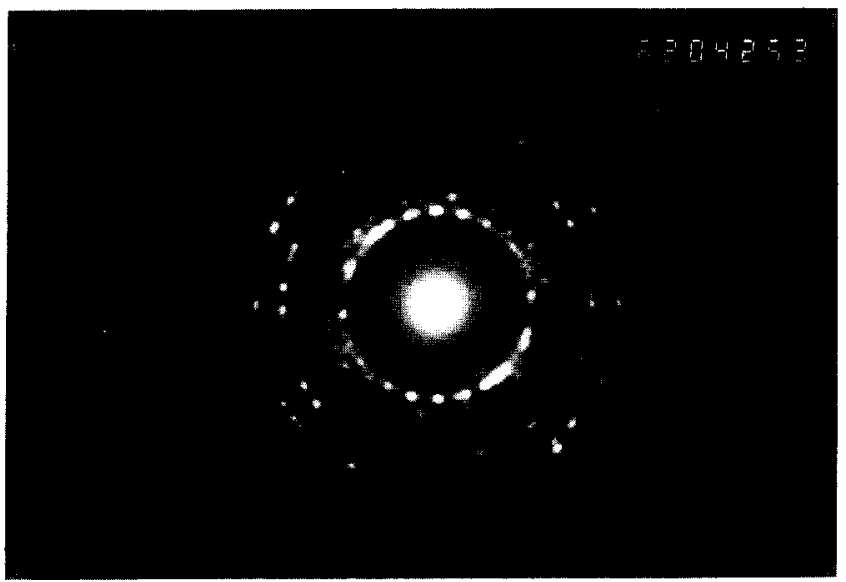

(b)

Fig. 8. (a) Transmission electron microscopy (TEM) image of the alumina film surface, deposited at $330^{\circ} \mathrm{C}$ with (b) the corresponding TEM diffraction ring patterns

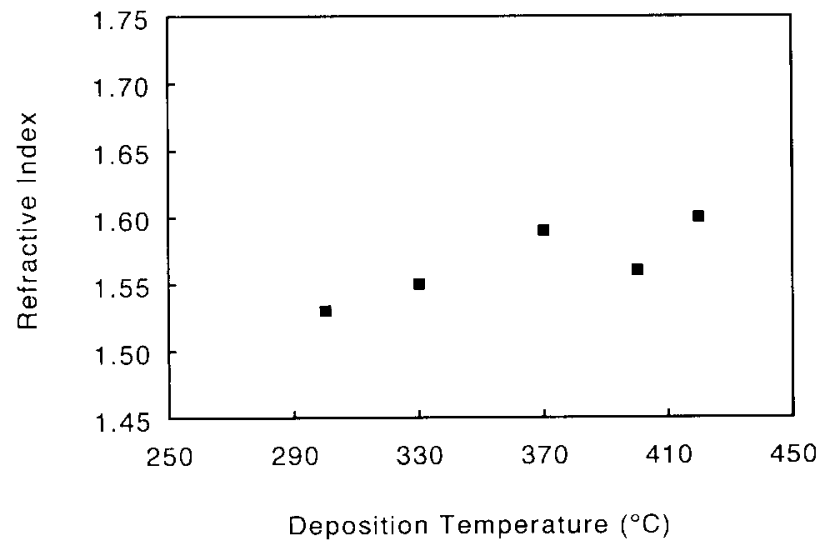

Fig. 9. Index of refraction of the alumina films deposited on AISI 304 as a function of the deposition temperature.

\section{Discussion}

The present study has shown that the protectiveness of the alumina films against high temperature corrosion increased when the deposition temperature of the MOCVD-deposited alumina films changed from 290 to $420^{\circ} \mathrm{C}$. The relative weight gain is reduced from more than $30 \%$ to less than $1 \%$, compared with the uncoated specimens. Corrosion products were found all over the surface, especially chain-like and single-crystal corrosion products, all iron-rich sulphides. The chain-like corrosion products were caused by the presence of cracks in the alumina films, related to the internal stress in the thin oxide film. These cracks are present even when high deposition temperatures are used. The presence of the cracks was explained [9] by intrinsic and thermal stresses. The thermal stress can be quantified, knowing the Young's modulus of the film and the thermal expansion coefficients of the film and the substrate. The amount of intrinsic stress is a function of several process parameters.

The single crystals of FeS were formed mainly as a result of the presence of fast diffusion paths such as pinholes. With increasing deposition temperature a significant change in this corrosion behaviour appeared. These single-crystal corrosion products have almost disappeared when the deposition temperatures increased to $420^{\circ} \mathrm{C}$. On the contrary, at high deposition temperatures the process is carried out in the diffusion-limited region resulting in a less uniform thickness of the coating, which was also confirmed by a high amount of diffusion rings on the specimens indicative of the diffusion-ratelimited deposition regime. Therefore, more research is necessary to deposite pore-free alumina films under reaction-rate-limited conditions.

One of the major advantages of the MOCVD process is the low temperature of formation of $\mathrm{Al}_{2} \mathrm{O}_{3}$ following

$$
\mathrm{Al}\left(\mathrm{s}-\mathrm{OC}_{4} \mathrm{H}_{9}\right)_{3} \stackrel{\Delta T}{\longrightarrow} \frac{1}{2} \mathrm{Al}_{2} \mathrm{O}_{3}+\text { products }
$$

On decomposition of ATSB, volatile products are also formed. The main products are water, 2-butanol and butene [24]. The porous structure and thus the low protectiveness of the alumina film can now be explained by an incomplete conversion of the ATSB molecules, mentioned above, especially at the lower deposition temperatures. Incorporation of $\mathrm{AlO}(\mathrm{OH}), \mathrm{H}_{2} \mathrm{O}$ or alcohol (responsible for the carbon impurities, but not found in alumina films from ATSB, as is discussed later) in the film will be possible. This was also suggested by Baryshnikov et al. [24] who reported that at low conversion of the $\mathrm{M}(\mathrm{OR})_{i}$ molecules, the corresponding alcohol was identified in amounts of up to 1 mole per mole of the substance being decomposed. The use of other precursors will probably lead to higher levels of impurities. For example, carbon impurities were also found by Temple and Reisman [21] who studied the thermally activated decomposition of aluminium hexafluoracetylacetonate from the gas phase to form alumina on silicon 
substrates. By means of X-ray photoelectron spectroscopy the approximate atomic concentration of carbon in the film was found to be in the range $3 \%-7 \%$ and increased with increasing substrate temperature during deposition. Kobayashi et al. [25] reported that low deposition temperatures of alumina from aluminium triisopropoxide produce a large carbon contamination. Pande et al. [26], studying the alumina deposition from trimethylaluminium and nitrous oxide as reactant sources, occasionally found carbon (less than $5 \%$ ). The presence of carbon is most likely a result of partial decomposition of the metal-organic precursor [24-27].

Furthermore, as well as the incorporation of $\mathrm{OH}$ groups or carbon, the $\mathrm{Al}: \mathrm{O}$ ratio also depends on the deposition temperature. Korzo [28] reported that low conversion temperatures will lead to a rupture of the weak $\mathrm{O}-\mathrm{R}$ bonds. At higher deposition temperatures rupture of the strong $\mathrm{Al}-\mathrm{O}$ bonds will also be possible. Therefore, the non-stoichiometry of the compound of the $\mathrm{AlO}_{x}$ with $x \neq 1.5$ depends also on the deposition temperature. Because of the relatively low accuracy of the methods of analysis and characterization, it was not possible to determine the aluminium:oxygen ratio exactly, but as a result of the low deposition temperatures it was not assumed that the $\mathrm{Al}-\mathrm{O}$ bond was ruptured.

To determine the presence of impurities in the alumina films, AES and FTIR measurements were carried out. AES was used for alumina films deposited between 300 and $400{ }^{\circ} \mathrm{C}$. From the AES depth profile and steady state Auger spectra (survey scan) it was found that no carbon was detected, or at least the carbon peak was below the background level. This means that the suggestion of Baryshnikov et al. [24] implying the incorporation of the corresponding alcohol was not confirmed. Even at lower deposition temperatures, such as $300^{\circ} \mathrm{C}$, no carbon was found or detected. Comparing our results obtained from the methods of analysis of the aluminadeposited AISI 304 from ATSB with the other results [24-27] it can be concluded that it is the use of the precursor ATSB that will lead to a very low level of carbon incorporation, which is smaller than the detection level of the AES technique.

With the FTIR functional groups were identified. It was found that the $\mathrm{H}-\mathrm{O}$ absorbance band decreases in intensity as the deposition temperatures increase. This indicates that fewer hydrogen atoms are incorporated into the film which can support the suggestion that the incorporation of $\mathrm{AlO}(\mathrm{OH})$ or $\mathrm{H}_{2} \mathrm{O}$ is much more acceptable than the incorporation of the alcohol or carbon.

The peak of $\mathrm{Al}-\mathrm{O}$ becomes sharper with increasing deposition temperature and shifts towards higher wavenumbers. The shift of the characteristic $\mathrm{Al}-\mathrm{O}$ peak around $900-950 \mathrm{~cm}^{-1}$ to higher wavenumbers with increasing deposition temperature may be explained by a lower concentration of $\mathrm{OH}$ groups in the alumina films, an increased effect of the contribution of the difference in thermal expansion, and by the higher deposition temperatures, which probably result in a significant decrease in the intrinsic stress in the alumina films.

The effect of stress on the peak position of several FTIR spectra of amorphous silica, deposited by the low pressure pyrolysis of organometallic precursors, was discussed previously by Desu [29]. It was found that a change in internal stress, either the intrinsic or the thermal stress, will have an effect on the stretching and bending band of the silica. Stress relaxation by annealing results in a positive shift of the $\mathrm{Si}-\mathrm{O}-\mathrm{Si}$ stretching band and a negative shift of the $\mathrm{Si}-\mathrm{O}-\mathrm{Si}$ bending band. According to Desu [29], annealing at high temperatures reduces the $\mathrm{Si}-\mathrm{O}-\mathrm{Si}$ bond angle strain which might explain the decrease in intrinsic stress with increasing deposition temperature. For the $\mathrm{Al}-\mathrm{O}$ system much less information [30] is available on the peak positions of the bending and stretching bands. Nothing is known about peak positions in relation to the internal stress of the alumina film and thus also nothing about the sign of the stress. Furthermore, the internal stress of the film, as shown by Desu [29], may also have an effect on the position of the characteristic Al-O peak.

As mentioned above, low deposition temperatures will result in larger amounts of $\mathrm{OH}$ groups and will probably contribute to the total stress and thus to the shift of the Al-O peak. Preliminary results in which water was added to the nitrogen gas flow showed that at lower deposition temperatures of $280^{\circ} \mathrm{C}$ and $330^{\circ} \mathrm{C}$ the $\mathrm{OH}$ band was much more pronounced with increasing water content $(0 \%-80 \%$ in ATSB). On the contrary, no shift towards higher wavenumbers was found for the $\mathrm{Al}-\mathrm{O}$ IR absorbance band. This means that the effect of $\mathrm{OH}$ incorporation on the positive shift of the $\mathrm{Al}-\mathrm{O}$ band can be neglected.

It is also clear that the characteristic Al-O IR absorbance band changed in shape. For low deposition temperatures, this peak was smooth and broad, but it becomes sharper with higher deposition temperatures. Morssinkhof [9] related this effect to the decrease in the amount of $\mathrm{OH}$, which has also a peak at $1050 \mathrm{~cm}^{-1}$. Kang and Chun [22] attributed this effect to the fact that in general the IR spectra of glassy or amorphous materials are smooth and broad, while those of crystalline materials are relatively sharp. This corresponds well to the results obtained from TEM. The TEM analysis indicates that microcrystalline phases were observed, between 8 and $20 \mathrm{~nm}$, at a deposition temperature of $330^{\circ} \mathrm{C}$ and increased in size with increasing deposition temperature. From the results above, the incorporation of impurities will have an effect on the broadening of the peak and intrinsic and thermal stress on the shift of the peak position. 
As already mentioned before, the structure of the alumina films was also determined by XRD and TEM. For all the coatings (deposition temperature $300-400^{\circ} \mathrm{C}$ ) $\mathrm{X}$-ray spectra did not exhibit any indexable alumina peak, revealing the amorphous character of the films. Kang and Chun [22] also reported that transmission electron micrographs of alumina films display electron diffraction patterns exhibiting interference rings at low deposition temperatures, indicative of an amorphous structure, and at higher deposition temperatures diffraction rings, indicative of an extremely fine grain size of the alumina film. This implies the absence of a longrange order in the chemical bonding of this material formed at temperatures between 300 and $400^{\circ} \mathrm{C}$. As shown in Fig. 9, the refractive index of the alumina film increases slightly with temperature, and lies between 1.53 and 1.60. Furthermore, no trend was observed with variation in the coating thickness. These low values of the refractive index correspond to the value for amorphous alumina $[12,22,31]$. The standard value for $\gamma$ alumina is about 1.7. Kang and Chun [22] suggested that the low value of the refractive index is also related to a low film density and hydrogen incorporation. From the corrosion experiments is was found that the porous structure decreased with increasing deposition temperature, indicative of a more densified structure of the alumina film. Ehle et al. [27] suggested that the higher index of refraction with increasing deposition temperature is due to a corresponding change in the microstructure of the films from the amorphous to the polycrystalline $\gamma$-phase. Temple and Reisman [21] reported that the low refractive index is also due to the presence of carbon impurities. Our results revealed no carbon impurities in the deposited alumina films, even at low deposition temperatures. As mentioned earlier, it was determined with FTIR measurements that higher deposition temperatures correspond to a lower $\mathrm{O}-\mathrm{H}$ peak. This means that our results agree well with those of Kang and Chun [22].

The MOCVD technique described in this paper allows low deposition temperatures for the formation of alumina films from ATSB. The alumina film contains no impurities except hydrogen, but cracks and pores are still present. This might be due to the presence of internal stress, a low resistance against thermal shock or an incomplete conversion of the precursor. Much more research is required to optimize the MOCVD process in order to obtain a dense, pore- and crack-free alumina film.

\section{Conclusions}

The pyrolytic decomposition of ATSB, carried out at atmospheric pressure in the low temperature range $290-420^{\circ} \mathrm{C}$ in nitrogen, resulted in the deposition of thin alumina films.

From the corrosion experiments it was observed that the protectiveness of the deposited alumina films increased with increasing deposition temperature. This is explained by a less porous structure of the film. Nevertheless, cracks are still present in the alumina films, owing to the presence of internal stress and/or a low thermal shock resistance.

From XRD measurements it was concluded that the alumina films, deposited on AISI 304, have an amorphous structure, even at the highest deposition temperature of $420^{\circ} \mathrm{C}$. However, with TEM analysis a very fine grain size (few nanometres) of $\gamma$-alumina was observed. The refractive index of the alumina film slightly increases with deposition temperature from 1.53 to 1.60 .

From the FTIR spectra it was shown that the amount of $\mathrm{OH}$ groups incorporated in the alumina film decreases as the deposition temperature increases. With AES no elements other than aluminium and oxygen were found. Carbon was not detected above the background level of the AES spectra, even for alumina films deposited at $300^{\circ} \mathrm{C}$.

\section{Acknowledgments}

This research was supported by the Innovative Research Program on Technical Ceramics (IOP-TK) with financial aid of the Dutch Ministry of Economic Affairs. Thanks are due to G. J. M. Weierink for the FTIR measurements, A. H. J, van den Berg (CMO) for the AES experiments, J. Boeijsma for the XRD measurements, K. Eijkel (MESA) for the ellipsometry measurements, and T. Kachlicki (CMO) for the TEM analysis, all at the University of Twente.

\section{References}

1 D. C. Bradley, Chem. Rev, 89 (1989) 1317.

2 D. C. Bradley, R. C. Mehrotra and P. D. Gaur, Metal Alkoxides, Academic Press, London, 1978.

3 P. Kofstad, High Temperature Corrosion. Applied Science, London, 1988.

4 L. Hall and B. Robinette, in J. M. Blocher, Jr., and J. C. Withers (eds.), Proc. 2nd Int. Conf., Electrochemical Society, New York, 1970.

5 V. M. Koleshko, V. V. Sviridov, V. P. Boldyrev, B. S. Reznikov, I. V. Nekaryukin, K. D. Yashin, N. N. Goroshko and A. A. Kovalevskii, Neorg. Mater., 12 (1976) 1780.

6 K. Kamata, European Patent Application EP O 055459 Al, 1981.

7 F. C. Eversteijn, Philips Res. Rep., 21 (1966) 379.

8 A. A. Barybin and V. I. Tomilin, Zh. Prikl. Khim., 49 (1976) 1699.

9 R. W. J. Morssinkhof, The deposition of alumina films on steels by MOCVD, Ph.D. Thesis, University of Twente, Enschede, 1991

10 J. A. Aboaf, J. Electrochem. Soc., 114 (1967) 948. 
11 M. T. Duffy, J. E. Carnes and D. Richman, Metall. Trans., 2 (1971) 667.

12 C. Dhanavantri, R. N. Karekar and V. J. Rao, Thin Solid Films, 127 (1985) 85.

13 A. A. Barybin, V. I. Tomilin, V. A. Kempel and E. A. Makhotin, Prib. Tekh. Eksp., 3 (1975) 238.

14 J. Saraie, J. Kwon and Y. Yodogawa, J. Electrochem. Soc., 132 (1985) 890.

15 M. Matsushita and Y. Koga, J. Electrochem. Soc., 115 (1968) 69C.

16 K. Okuyama, Y. Kousaka, N. Tohge, S. Yamamoto, J. J. Wu, R. C. Flagan and J. H. Seinfeld, AIChE J., 32 (1986) 2010.

17 T. T. Kodas, A. Sood and S. E. Pratsinis, Powder Technol., 50(1) (1987) 47.

18 K. J. Sladek and W. W. Gibert, Proc. Eur. Cong. CVD, (1972) 215.

19 R. C. Wilhoit, J. Phys. Chem., 6 I (1957) 114.

20 T. Ito and Y. Sakai, Solid State Electron., 17 (1974) 751.
21 D. Temple and A. Reisman, J. Electron. Mater., 19(9) (1990) 995.

22 C. J. Kang and J. S. Chun, Thin Solid Films, 189 (1990) 173.

23 V. A. C. Haanappel, H. D. van Corbach, T. Fransen and P. J. Gellings, Thin Solid Films, 230 (1993) 138.

24 Y. Y. Baryshnikov, I. L. Zakharov and G. I. Makin, Zh. Obshch. Khim., 60(6) (1990) 1350.

25 T. Kobayashi, M. Okamura, E. Yamaguchi, Y. Shinoda and Y. Hirota, J. Appl. Phys., 52 (1981) 6434.

26 K. P. Pande, V. K. R. Nair and D. Gutierrez, J. Appl. Phys., 54(9) (1983) 5436.

27 R. S. Ehle, B. J. Baliga and W. Katz, J. Electron. Mater., 12(3) (1983) 587.

28 V. F. Korzo, Zh. Prikl. Khim., 49(1) (1975) 74.

29 S. B. Desu, Mater. Res. Soc. Symp. Proc., 168 (1990) 221.

30 L. D. Frederickson, Anal. Chem., 26 (1954) 1883.

31 L. G. Meiners, Thin Solid Films, 113 (1984) 85. 